\title{
Impacts of woody invasive alien plant species on rural livelihood: Generalized propensity score evidence from Prosopis spp. invasion in Afar Region in Ethiopia
}

\author{
Ketema Bekele $^{1 *}$, Jema Haji ${ }^{1}$, Belaineh Legesse ${ }^{1}$, Hailu Shiferaw ${ }^{2}$ and Urs Schaffner ${ }^{3}$
}

\begin{abstract}
This study applied a generalized propensity score method to evaluate the impact of Prosopis invasion on Afar pastoralist and agro-pastoralist households' annual per capita consumption expenditure, as a proxy of rural livelihoods. The analysis was based on cross-sectional survey data collected in mid-2016 from 250 households in the Afar National Regional State in Ethiopia. The method was applied to match households with similar covariates with different Prosopis invasion levels. The method was effective in teasing out non-linear causal relationships between Prosopis invasion dose and household per capita consumption expenditure. Average dose-response or impact function was obtained by estimating average annual household per capita consumption expenditure at different levels of Prosopis invasion. Initially, the plants' impact was positive, but turned negative after an optimum invasion dose. The optimal invasion dose of Prosopis was found to be $22.23 \%$. The corresponding optimum level of annual household per capita consumption expenditure was found to be 4,500.50 Ethiopian Birr (USD 198). The results suggest that to maximize the benefits of Prosopis and minimize its adverse effects on the livelihoods of the pastoral and agro-pastoral communities, diverse management strategies that take into account not only the intensity of invasion, but also patterns of dryland economy should be implemented.
\end{abstract}

Keywords: Invasive alien species, Prosopis, Generalized propensity score, Dose-response function, Consumption expenditure

\section{Introduction}

Invasive alien species (IAS) re-engineer natural and semi-natural ecosystem integrity and have global consequences mainly on ecosystems goods and services, while ultimately affecting the livelihoods of local households (Gordon 1998; Pimentel et al. 2001; MA 2005; Wardle et al. 2011; Wise et al. 2012). As IAS re-engineer biodiversity of a recipient ecosystem, some new ecosystem services are added while some existing ecosystem services are lost (Pejchar and Mooney 2009; Simberloff et al. 2013). In the pastoral drylands of the Afar National Regional State in Ethiopia (here after referred to as Afar), Prosopis spp. (hereafter referred to as Prosopis) was intentionally introduced in the late 1970 s to tackle

\footnotetext{
* Correspondence: ketmimi@yahoo.com

${ }^{1}$ School of Agricultural Economics and Agribusiness, Haramaya University,

P.O. Box 50, Dire Dawa, Ethiopia

Full list of author information is available at the end of the article
}

desertification (Sertse and Pasiecznik 2005). The plant has both positive and negative effects in areas where it has rapidly expanded (Ilukor et al. 2016; Rogers et al. 2017; Tilahun et al. 2017).

This drought-resistant species is a source of income for pastoral households of the study area. The region's poor produce charcoal from the offcuts of the plant and sell that on roadsides to generate income (Admasu 2008; Haregeweyn et al. 2013; Mehari 2015; Ilukor et al. 2016). The plant also has ecological benefits in the region. Previous studies indicated the plant's role in regulating microclimate, improving soil fertility, controlling soil erosion and desalinizing soils (Berhanu and Tesfaye 2006; Ayanu et al. 2015). However, the plant has depressive effect on beneficial native species (van Wilgen et al. 2001). It easily encroaches onto paths, villages, homes, water sources, crop and pasturelands. The thorns of the plant cause severe injuries to the hooves of animals and have equally serious 
human health consequences (Mwangi and Swallow 2008; Mehari 2015; Maundu et al. 2009; Ilukor et al. 2016). The plant swiftly invades a huge tract of pasturelands and causes rangeland and pastureland deterioration, thereby severely affecting households' income from livestock production (Wakie et al. 2016; Zeray et al. 2017). It also indirectly increases household health spending (Ayanu et al. 2015; Haregeweyn et al. 2013; Rogers et al. 2017).

To date, different quantitative studies have addressed the diverse impacts of Prosopis on the pastoral communities of the Afar and other similar areas in East Africa (e.g. Mwangi and Swallow 2008; Maundu et al. 2009; Haregeweyn et al. 2013; Haji and Mohammed 2013; Mehari 2015; Zeray et al. 2017). These studies assumed that the effects are fixed, average and uniform for all households regardless of plant invasion intensity. Considering Prosopis invasion as binary, the studies reported that the average effect of invasion is the outcome of the difference between the invaded areas (treatment groups) and non-invaded areas (control groups). The studies employed average treatment impact analyses with the assumption that all of the treated areas or localities have the same level of invasion and so do the households.

However, these studies have two limitations. First, since all of the Prosopis-invaded areas do not experience the same level of intensity, simple average impact analysis that relies on a conventional binary treatment approach cannot provide a detailed analysis. Examining the non-linear distribution of impacts provides a more accurate picture of the impact (Zhai et al. 2010; Kassie et al. 2014; Liu and Florax 2014; Li and Fraser 2015). Second, as a woody plant, Prosopis is used as a source of income for some groups in the region (Ayanu et al. 2015). Given the positive and negative effects of the plant, it is not logical to determine its effects based on average results. It is rather important to determine where costs for managing it exceed its discernible benefits (Mwangi and Swallow 2008), since the plant's benefits may outweigh its negative effects up to some invasion dose (intensity), though the unchecked expansion can cause its costs to overweigh its benefits (van Wilgen and Richardson 2014). These empirical results generally emphasize the importance of uniform or blanket-type policy incentives and management options for different impacts (e.g. Mwangi and Swallow 2008; Maundu et al. 2009; Haji and Mohammed 2013; Zeray et al. 2017). However, the effectiveness and sustainability of such uniform policy incentives is questionable (Fraser et al. 2011; Kassie et al. 2014). In connection with this, Shackelford et al. (2013) convincingly contended that finding a middle ground via trade-offs and socio-ecological complexities in IAS management processes is a vital step towards offering viable solutions.
The ecological and socio-economic impact of Prosopis is positively associated with its level and intensity of expansion. Therefore, evaluating the impacts of invasion at varied dosage levels (the dose-response relationship) and determining the optimum level of invasion are important steps towards forging feasible policy recommendations. The chief hypothesis of the current study is that the positive effect of Prosopis implied in its lower level of invasion (with per capita consumption expenditure used as a proxy) outweighs its negative effects. In contexts where the plant is sparsely populated, its adverse effect on income generated from livestock is less than the income generated from charcoal burning (Shackleton et al. 2006). However, in pastoral areas where livestock production is the main source of livelihood, the plant's invasion has adverse effects since it causes pastureland deterioration and encroaches into water sources. Its invasion also has severe health implications both on animal and human populations (Ilukor et al. 2016).

The aim of this paper is, therefore, to evaluate whether the intensity of Prosopis invasion has a negative or positive effect on household per capita consumption expenditure and to examine the extent to which the effect varies with differences in the intensity levels of its invasion.

\section{Study area}

The Afar National Regional State (hereafter referred to as the Afar Region) in Ethiopia is part of the Great Rift Valley of East Africa. The region is located between $39^{\circ} 34^{\prime}$ and $42^{\circ} 28^{\prime}$ East longitude and $8^{\circ} 49^{\prime}$ and $14^{\circ} 30^{\prime}$ North latitude in the northeastern part of Ethiopia covering about $270,000 \mathrm{~km}^{2}$ (CSA 2008). The region covers about $10 \%$ of the total landmass of Ethiopia and about $29 \%$ of pastoral lowlands. It is arid and semi-arid with a mean annual temperature of $31{ }^{\circ} \mathrm{C}$. Rainfall is erratic and scarce with annual precipitation between 200 and $600 \mathrm{~mm}$. The major watershed in the region is the Awash River Basin. The population is about 1.77 million (CSA 2015). The production system of the region is dominated by pastoralism (90\%) from which agro-pastoralism $(10 \%)$ is now emerging following small-scale irrigation schemes developed on some permanent and temporary rivers. The Afar pastoralists and agro-pastoralists highly depend for their livelihood on floodplains of the Awash River where they graze their livestock during the drought period and practice small-scale agriculture. Some recent studies revealed that the floodplains are either invaded or are under risk of invasion by Prosopis (Ayanu et al. 2015; Ilukor et al. 2016).

The dominant vegetation types in the study area are bushlands, shrublands, riverine forests, grasslands and seasonal marshes and swamps. Prosopis has recently encroached into all of these vegetations. 


\section{Methods}

\section{Sampling procedure}

The study was based on pre-tested cross-sectional survey data collected during mid 2016 from 253 randomly selected pastoral dominated households in three selected districts in Gabi Rasu zone of Afar National Regional State in Ethiopia. The sample households were drawn and interviewed, with replacement, based on probability proportionate to the relative size of households in selected kebeles. In Ethiopia, every kebele administrator has full list of households living in the administrative unit. We used this list as a sampling frame. When the randomly selected household head or an adult family member of that household refused the interview or was not around, he/she would be replaced by the next household on the list taken. Surveys were administered by trained local enumerators, who were with a minimum of diploma degree, experience in administering similar surveys and fluent in local language.

\section{Outcome and treatment variables}

Our interest here is to investigate the effect of Prosopis invasion density or dose (treatment) on rural household livelihood (outcome). In measuring the livelihood of a household, the competing variables are income and consumption expenditures (Ellis 1993). Empirical literature indicates that consumption is smoother and less-variable than income in ranking rural households' livelihood status (e.g. McCulloch and Baulch 1999; Baulch and Hoddinott 2000; Matuschke and Qaim 2008). In the current study, annual household per capita consumption expenditure, a main outcome variable, was used as a proxy for indicating a household's livelihood status (Table 1).

While Prosopis invasion has positive effects on household per capita consumption expenditure through income from charcoal, it has negative effects via income from livestock. Prosopis invasion also directly increases household health expenditure (for both human and livestock) mainly through its thorn infections Haregeweyn et al. 2013; Ayanu et al. 2015). The invasion also increases household

Table 1 Descriptive statistics of variables

\begin{tabular}{|c|c|c|c|c|c|}
\hline Variable & Variable description & Mean & Std. dev. & Min & Max \\
\hline \multicolumn{6}{|c|}{ Treatment variable } \\
\hline Invasion & Average fractional cover of land invaded by Prosopis within 100-m radius of a household's homestead (\%) & 33 & 16 & 0.4 & 71 \\
\hline \multicolumn{6}{|c|}{ Outcome variables } \\
\hline HHExp & Annual household per capita consumption expenditure (in ‘000 Birr) & 3.58 & 0.33 & 0.23 & 5.30 \\
\hline Incmerop & Annual household income from crop production (in '000 Birr) & 9.19 & 1.19 & 0 & 19.65 \\
\hline Incmlivstk & Annual household income from livestock production (in '000 Birr) & 16.88 & 2.29 & 0 & 83.41 \\
\hline Incmchard & Annual household income from charcoal and fuel wood selling (in '000 Birr) & 7.94 & 1.88 & 0 & 27.00 \\
\hline Exphealth & Annual household per capita health expenditure (in ‘000 Birr) & 0.47 & 0.66 & 0 & 4.50 \\
\hline \multicolumn{6}{|l|}{ Covariates } \\
\hline TLU & Number of livestock (tropical livestock unit) ${ }^{1}$ & 16.49 & 6.11 & 0 & 170 \\
\hline Assetval & Fixed asset value of main household properties (in '000 Birr) & 5.71 & 0.23 & 0 & 7.03 \\
\hline HHsize & Number of individuals living under the same roof & 5.32 & 2.04 & 1 & 12 \\
\hline Sex & Sex of household head ( $1=$ male; 0 = female) & .93 & - & - & - \\
\hline Age & Age of a household head (year) & 40.71 & 12.56 & 20 & 80 \\
\hline Edu & Average education of a household members (years of schooling) & 1.51 & 1.54 & 0 & 9 \\
\hline NFIncm & Any household income source out of livestock and crop production ( $1=$ yes; $0=$ no $)$ & 0.78 & - & - & - \\
\hline Aid & Any aid from governments and/or non-governments ( 1 = yes; 0 = no) & 0.98 & - & - & - \\
\hline Participation & Social participation of a household member in informal and/or formal institutions ( $1=$ yes; $0=$ no) & 0.35 & - & - & - \\
\hline Credit & Access to formal and/or informal credit ( $1=$ yes; $0=$ no) & 0.11 & - & - & - \\
\hline Dist_mkt & Distance to the nearest market centre (kilometres) & 19.53 & 14.67 & 0.02 & 52 \\
\hline Nrm_expert & Number of contacts a household head with natural resources management expert(s) in the year & 8.96 & 2.06 & 0 & 50 \\
\hline Dist_watrp & Distance to the nearest water point (kilometres) & 1.76 & 0.43 & 0.01 & 50 \\
\hline Dist_healt & Distance to the nearest health post (kilometres) & 3.39 & 5.42 & 0.02 & 40 \\
\hline Dist_school & Distance to the nearest school (kilometres) & 2.41 & 5.26 & 0.01 & 60 \\
\hline
\end{tabular}


health expenditure through malaria incidence by hosting mosquitoes (Silva et al. 2007). With the assumption that total household income is a constraint, this increment of household health expenditure in turn reduces household per capita consumption expenditure. In such intricate effects of Prosopis on a household's livelihood, using ultimate livelihood indicators such as per capita consumption expenditure seems plausible in representing the aggregate effect. In the analysis, this main outcome variable is made net of household health expenditure.

Making household consumption expenditure net of health expenditure justifies the unique or independent effects of Prosopis among households. The issue is that in pastoralist communities, the main income which is from livestock production is supposed to be affected uniformly by Prosopis, because households from a given locality have common pasture lands and water points for their livestock. This situation creates difficulty of untangling the unique effects of Prosopis on particular households compared to other neighboring households (Khandker et al. 2010; Gertler et al. 2011).

To alleviate this problem, we used household per capita consumption expenditure which is net of household per capita health expenditure. We argue that this net consumption expenditure differs among households from a given locality. A household's family members and livestock with dense Prosopis surrounding its permanent homestead are more likely to be harmed by Prosopis thorns than its counterpart household having low Prosopis density surrounding its homestead. This implies that households with high Prosopis density surrounding their homestead incur more household health expenditures than their counterparts. Therefore, household per capita consumption expenditure net of household health expenditure identifies the unique Prosopis effect on a household.

In sensitivity analysis, household income from livestock, household income from charcoal and fuel wood and household health expenditure were included as outcome variables (Table 1). These outcome variables were included to see their relationship with Prosopis invasion dose and the implication of that relationship on household per capita consumption expenditure.

The treatment is Prosopis invasion intensity which is measured by the proportion of land covered by Prosopis within 100-m radius of a household's permanent residence and is a continuous variable (Table 1). Average Prosopis cover attributed to each sample household was computed using a Random Forest algorithm. The centre point for a household was a coordinate point collected during the survey. Then, pixel level fractional cover of Prosopis was averaged within 100-m radius of this point. Images were acquired by the Landsat 8 (OLI) on 26 and 28 January as well as 11 and 20 February 2016 (paths
167 and 168; rows 50 to 54). These acquisition dates match the period of field data collection and fall into the study area's dry season, when herbs and grasses are dry and most trees and bushes except Prosopis have shed their leaves. Finally, regression analyses were done to produce spatial cover distributions (fractional cover) for each sample household.

The estimated distribution of invasion among our sample households covers large ranges of invasion intensity and is approximately normally distributed (Figure 1). Zero invasion level was not included implying that non-invaded or a control group is not considered as our main analysis is DRF and its average.

\section{Control variables (covariates)}

In observational or non-experimental impact researches, covariates selection criteria are critical ( $\mathrm{Li}$ and Fraser 2015) as, by its very definition, propensity score is the probability which an agent takes treatment, given covariates. Fundamentally, it involves identifying and controlling confounding variables. The general rule of thumb is to include all covariates that have association with both treatment and outcome variables (Seeger et al. 2007; Patorno et al. 2013). However, Rubin (1997) and Brookhart et al. (2006) propose that including covariates that have association with an outcome variable regardless of their association with a treatment variable is useful to reduce variance of estimated treatment effect. There is thus a chance that a variable related to the outcome is also related to treatment (Garrido et al. 2014).

On the other hand, Brookhart et al. (2006) warn that instrumental variables should not be included in covariates in matching models. They argue that an instrumental variable increases treatment effect variance. However, since in most cases instrumental variables are hardly identified in practice, Myers et al. (2011) recommend inclusion and adjustment rather than total exclusion of

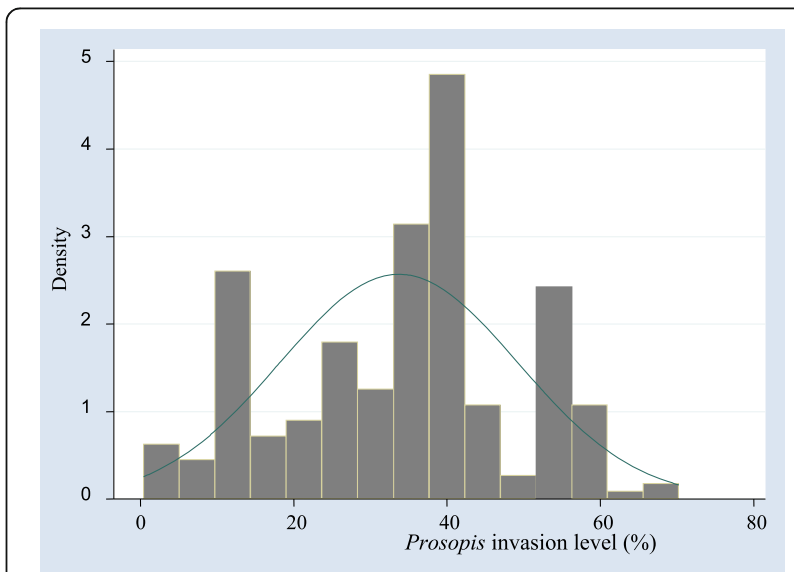

Figure 1 Distribution of estimated Prosopis invasion among sample households 
such variables. Unlike binary impact analysis, in DRF analysis, the richness of covariates may strengthen the assumption of unconfoundedness (Kluve et al. 2012). However, especially in smaller datasets, potentially irrelevant covariates may introduce too much "noise" into treatment effect estimates and obscure reduction in biases (Brookhart et al. 2006; Ho et al. 2007). Considering all concerns associated with covariates selection, Garrido et al. (2014) suggest that covariate selection should be guided by the trade-offs between the effects of variables on potential bias (distance of estimated treatment effect from true effect) and efficiency (precision of estimated treatment effect).

In the light of the above arguments and drawing on other theoretical and empirical works (e.g. Seid 2012; Haji and Mohammed 2013; Mehari 2015; Zeray et al. 2017) that emphasize association of each variable with Prosopis invasion density and household per capita consumption, this study included different relevant demographic and socio-economic variables as covariates (Table 1 ).

\section{Econometric model specification for continuous treatment impact evaluation: Generalized propensity score method}

In social sciences researches where a treatment is not randomized, propensity score matching (PSM) is a plausible impact evaluation method (Rosenbaum and Rubin 1983). It is a way of mimicking randomization to develop a counterfactual or control group that is as similar to the treatment group as possible in terms of observed characteristics and analyzing the average treatment effect. This standardized PSM method is usually applied when a treatment is binary. However, many social interventions like Prosopis cover are continuous in their nature and take value in a continuum. In continuous intervention impact analysis, GPS method is a plausible method for estimating dose-response function (Hirano and Imbens 2004). Application of the method in other social sciences impact assessment researches produced good results (e.g. Bia and Mattei 2007; Kluve et al. 2012; Zhai et al. 2010; Kassie et al. 2014; Liu and Florax 2014; Li and Fraser 2015).

GPS method is a helpful method tool to account for imbalance in covariates among agents from different doses of a treatment (Bia and Mattei 2007; Kluve et al. 2012). In the case of the current study, GPS is a single score that represents the probability of a household to be invaded by Prosopis conditional on a set of observed covariates or pre-invasion household characteristics. A GPS-based data is created to balance covariates between individuals from different invasion doses. This makes easier the task of isolating the effect of an invasion. In other words, GPS helps eliminate any potential biases associated with differences in covariates (Hirano and
Imbens 2004; Guo and Fraser 2010). Given weak unconfoundedness assumption, selection of Prosopis-invaded households to different intensity levels is random conditional on observable pretreatment variables.

The econometric model that fits well with GPS matching method is the potential outcome framework developed by Rosenbaum and Rubin (1983). Assuming a random sample of units from a large population and indexed by $i=1, \ldots, N$. For each unit $i$ under treatment level $t$, there is a set of potential outcomes $\left\{Y_{i}(t)\right\} t \in T$ referred to as the unit-level dose-response function (DRF). In the binary treatment case, $T=\{0,1\}$. However, in continuous treatment cases such as Prosopis invasion with different intensity levels, $T$ is in an interval $\left[t_{0}, t_{1}\right]$, with $t_{0}>0$ (Hirano and Imbens 2004). As the focus in GPS application is on average dose-response and marginal treatment functions for households who are invaded by Prosopis, households who are not affected by Prosopis invasion were not included in the study. Usually, in impact studies, missing data is an inherent problem. In such a case, the most important concern is identifying the curve of average potential outcomes (Bia and Mattei 2007; Guardabascio and Ventura 2013). In other words, the main objective of the study becomes estimation of the average potential outcomes or the entire average dose-response function, $\mu(t)=E\left[Y_{i}(t)\right]$, which in this study represents the function of the average per capita consumption expenditure over all possible Prosopis invasion intensities, and $Y_{i}(t)$ is the annual consumption expenditure for an invasion-affected household. The observable variables for a household $i$ are a vector of covariates $X_{i}$.

The GPS method is applied under weak unconfoundedness assumption. The assumption states that after controlling for observable characteristics $X_{i}$, any remaining difference in invasion intensity $T_{i}$ across households is independent of the potential outcomes $Y_{i}(t)$. In other words, after balancing on covariates, no reverse causality is expected $\left(Y_{i}(t) \perp T_{i} / X_{i}\right.$ for all $t \in T$ ) (Hirano and Imbens 2004). Empirical works on matching methods demonstrated that when treatment assignment is ignorable given the observed covariates, it is also ignorable given the balancing PS (Rosenbaum and Rubin 1983). Under weak unconfoundedness assumption, the average doseresponse function can be obtained by estimating the average outcomes of the sub-populations defined by covariates and different levels of treatment.

GPS method has a balancing property similar to PS for binary treatments. Defining $r(t, x)=f_{T / X}(t / x)$ as the conditional density of the treatment given the covariates, GPS is expressed as $R_{i}=r\left(T_{i}, X_{i}\right)$. When strata have the same value of $r(t, X)$, the probability that $T=t$ does not depend on the value of $X$. In other words, GPS has the property that

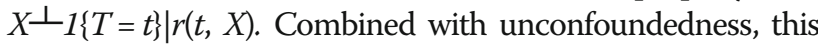


property implies that assignment to treatment is unconfounded given the GPS result.

Following Hirano and Imbens (2004), GPS method has implemented in three steps. In the first step, GPS was estimated as a conditional density of invasion given the covariates assuming normal distribution of invasion $(\beta(t, r)=E[Y / T=t, R=r])$. This assumption was tested using Kolmogorov-Smirnov (k-s) goodnessof-fit test, which is a non-parametric test used to decide if an observed random sample comes from an assumed normal continuous distribution. The k-s test is defined by the null hypothesis that the data follow normal distribution. The parameters of the invasion function $\beta_{0}, \beta_{1}$ and $\delta^{2}$ (conditional distribution of invasion) were estimated using maximum likelihood by employing Eq. (1).

$$
T_{i} / X_{i} \sim N\left[\beta_{0}+\beta_{1} X_{i}, \delta^{2}\right]
$$

As the main purpose for estimating the GPS is to ensure balancing of covariates across invasion categories, test for sufficient covariate balancing property of the estimated GPS was conducted before proceeding to step two. Following the estimation of the parameters of the invasion function in Eq. (1), GPS was estimated using Eq. (2).

$$
\hat{R}_{i}=\frac{1}{\sqrt{2 \pi \delta^{2}}} \exp \left[-\frac{1}{2 \hat{\delta}^{2}}\left(T_{i}-\hat{\beta}_{0}-\hat{\beta}_{0}^{\prime} X_{i}\right)^{2}\right]
$$

The second step involved modeling of the conditional expectation of household consumption expenditure $\left(Y_{i}\right)$ as a quadratic function of observed treatment $\left(T_{i}\right)$, estimation of GPS $\left(\mathrm{R}_{i}\right)$ and analysis of the interaction between the two using Eq. (3).

$$
\begin{aligned}
\beta(t, r)=g\left(\left[Y_{i} / T_{i}, \hat{R}_{i}\right]\right)= & \alpha_{0}+\alpha_{1} T_{i}+\alpha_{2} T_{i}^{2} \\
& +\alpha_{3} \hat{R}_{i}+\alpha_{4} \hat{R}_{i}^{2} \\
& +\alpha_{5} T_{i} \hat{R}_{i}
\end{aligned}
$$

Since the outcome variable of the study is continuous, $g$ was estimated using normal regression model. Finally, the average dose-response function at a particular value of the treatment $t$ was estimated by averaging the (estimated) conditional expectation $\mu(t)$ over the GPS at that level of invasion $(\mu(t)=E[\beta(t, r(t, X))], t \forall \mathrm{T})$ using Eq. (4).

$$
\begin{aligned}
\mu(t)=E[\hat{Y}(t)]= & \frac{1}{N} \sum_{i=1}^{N} g^{-1}\left[\hat{\alpha}_{0}+\hat{\alpha}_{1} \cdot t+\hat{\alpha}_{2} \cdot t^{2}+\hat{\alpha}_{3} \cdot \hat{r}\left(t, X_{i}\right)\right. \\
& \left.+\hat{\alpha}_{4} \cdot \hat{r}\left(t, X_{i}\right)^{2}+\hat{\alpha}_{5} \cdot t \hat{r}\left(t, X_{i}\right)\right]
\end{aligned}
$$

$\hat{\alpha}$ is the vector of parameters estimated in step two and $\hat{r}\left(t, X_{i}\right)$ is the predicted value of $r\left(t, X_{i}\right)$ at level $t$ of the treatment. The entire dose-response function was obtained by estimating this average potential outcome for each level of invasion. Plots of the average dose-response functions and marginal treatment effect functions, were shown graphically.

The average dose-response function shows the magnitude and the nature of the causal relationship between invasion and household per capita consumption expenditure. The DRF model was analyzed in STATA version 13 package using "doseresponse2" command developed by (Guardabascio and Ventura 2013).

\section{Results and discussion}

\section{Descriptive statistics}

The data obtained from informant interviews and focus group discussions suggested that the sample households from Amibara District were relatively highly invaded by Prosopis while households from Awash Fentale were relatively less invaded (Table 2). The minimum values of the invasion level were greater than zero. This indicates that all the sample households were selected from Prosopis-invaded areas. That is in line with the general assumption of an application of the GPS method which posits that in order to estimate DRF, all sample units should be from treatment group but at different dose levels. The mean invasion of sample households from Amibara was found to be higher than the total sample

\begin{tabular}{|c|c|c|c|c|}
\hline & Mean & Std. dev. & Min & Max \\
\hline Average fractional cover of Prosopis (Amibara) & 43 & 15 & 0.4 & 71 \\
\hline Average fractional cover of Prosopis (Awash Fentale) & 27 & 15 & 0.3 & 59 \\
\hline Average fractional cover of Prosopis (Gewane) & 29 & 16 & 0.4 & 42 \\
\hline Household per capita consumption expenditure (Amibara) & $3,120.69$ & $2,529.78$ & 226 & 14,500 \\
\hline Household per capita consumption expenditure (Awash Fentale) & $3,751.36$ & $3,740.89$ & 616.67 & 25,295 \\
\hline Household per capita consumption expenditure (Gewane) & $4,658.14$ & 4,397.72 & 963.33 & $20,583.33$ \\
\hline
\end{tabular}
households' mean invasion (33\%; see Table 1) while it was less for the other two districts. On average, the highest and the lowest household per capita consumption expenditures were observed in Gewane and Amibara districts respectively (Table 2 ).

Table 2 District disaggregated Prosopis invasion level and household per capita consumption expenditure

Source: own survey results, 2016 
The correlation between Prosopis invasion intensity and household per capita consumption expenditure prior to covariates adjustment appears to be generally negative (Figure 2). This result shows the average linear relationship of the treatment and outcome variables, but does not indicate any causality. This means that without any implication for causal inference, household per capita consumption expenditure decreases with increase in Prosopis in invasion intensity.

Disaggregating sample households showed differences in Prosopis invasion levels across the three sample districts in the region. It was observed that $33.20,30.43$ and $36.36 \%$ of the sample households were from low, medium and high invasion levels, respectively (Table 3). The disaggregation was made by cutting the invasion distribution at the 30th and 70th percentiles which roughly divided the sample households into three equal groups (invasion $\leq 26 \%$ low; $26<$ invasion $<41 \%$ medium and $\geq 41 \%$ high).

$F$ test and chi-square test results indicated statistically significant differences in terms of some covariates among households from different invasion levels (Table 4). The results imply that some pretreatment variables have association with invasion level. This in turn reveals violation of the key assumption (weak unconfoundedness). For instance, chi-square test at $10 \%$ significance level revealed that there is difference in income diversification among households with low, medium and high invasion levels (Table 4). Shrinkage in pasture and water resources appears to have forced pastoralists to drop their livestock production and resort to other means of income generation (Müller-Mahn et al. 2010). In areas where it has intensively expanded, Prosopis dwindled the pastoralists' traditional capacity to keep large herds of livestock. This situation obliged them to engage in non-farm income-generating activities to survive (Berhanu and Tesfaye 2006; Inkermann 2014). The study indicated that livestock holding of a TLU in medium invaded areas

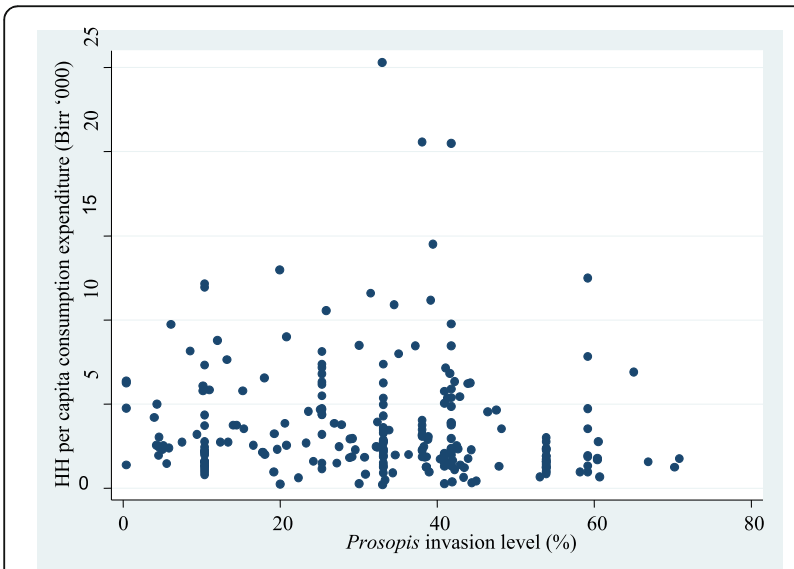

Figure 2 Household per capita expenditure and Prosopis invasion level before an adjustment. $\mathrm{HH}$, household
Table 3 Prosopis invasion levels of sample households among sample districts

\begin{tabular}{|c|c|c|c|c|c|c|c|c|}
\hline \multirow[t]{2}{*}{ Invasion level } & \multicolumn{2}{|c|}{ Amibara } & \multicolumn{2}{|c|}{ Awash Fentale } & \multicolumn{2}{|c|}{ Gewane } & \multicolumn{2}{|c|}{ Total } \\
\hline & No. & Perc & No & Perc & No & Perc & No & Perc \\
\hline Low & 34 & 13.44 & 35 & 13.83 & 15 & 5.93 & 84 & 33.20 \\
\hline Medium & 37 & 14.62 & 38 & 15.02 & 10 & 3.95 & 77 & 30.43 \\
\hline High & 57 & 22.53 & 11 & 4.35 & 16 & 6.32 & 92 & 36.36 \\
\hline Total & 128 & 50.59 & 84 & 33.20 & 41 & 16.21 & 253 & 100.00 \\
\hline
\end{tabular}

Source: own survey results, 2016

was greater than that of low and high invaded areas. $F$ test result also revealed that the difference is significant $(F=$ 8.532) (Table 4). This entails that since it outcompetes important indigenous grass species, Prosopis reduces the availability of forage (Wakie et al. 2016) and hence the TLU (Mehari 2015). Therefore, to get weak unconfoundedness assumption work, GPS matching method is a solution.

\section{Econometric results}

\section{Estimation of generalized propensity scores}

The conditional distribution of Prosopis invasion was estimated using Eq. (1) (Table 5). Before estimating GPS, the goodness-of-fit test was conducted (Additional file 1). Prosopis invasion per 100-m radius of a household's permanent residence, which is the dependent/treatment variable, was assumed to be normally distributed and tested. Applying Kolmogorov-Smirnov equality-of-distributions test, normal distribution of the disturbances is satisfied. The assumption of normality is statistically satisfied at .05 level with small values of Skewness $(-0.80)^{1}$ and Kurtosis $(2.59){ }^{2}$

Table 5 shows the coefficients and robust standard errors estimation of Eq. (1). To allow non-linear relationship between invasion dose and other variables, quadratic and cubic terms of main covariates and outcome variable (household per capita consumption expenditure) were included. Based on these estimates, the GPS for each household was estimated using Eq. (2). ${ }^{3}$

\section{Test for covariate balance}

After estimation, the covariates balancing property of GPS was checked. Table 6 shows results of the balancing test within each invasion interval. This was checked by testing the conditional mean of the pre-treatment variables or covariates since the GPS was not different between households that belong to a particular treatment group and between those that belong to other treatment groups. When the test fails to reject the hypothesis that the two sets of households are statistically indifferent, there is more confidence to believe that the treated and control groups matched by the GPS are balanced (Liu and Florax 2014). Following Hirano and Imbens's (2004) procedure, the balancing property of GPS was assessed by cutting the distribution of invasion at 30th and 70th 
Table 4 Scio-economic characteristics of sample households by invasion level

\begin{tabular}{|c|c|c|c|c|c|c|}
\hline \multirow[t]{2}{*}{ Dummy variables } & & \multicolumn{3}{|c|}{ Invasion level } & \multirow[t]{2}{*}{ Total } & \multirow[t]{2}{*}{$x^{2}$ value } \\
\hline & & Low & Medium & High & & \\
\hline \multirow[t]{3}{*}{ Sex } & Female & 8 & 3 & 7 & 18 & 4.514 \\
\hline & Male & 71 & 99 & 65 & 235 & \\
\hline & Yes & 52 & 66 & 49 & 167 & \\
\hline \multirow[t]{2}{*}{ Aid } & Not Received & 0 & 2 & 4 & 6 & $5.146^{*}$ \\
\hline & Received & 79 & 100 & 68 & 247 & \\
\hline \multirow[t]{2}{*}{ Participation } & No & 55 & 58 & 52 & 165 & $5.371^{*}$ \\
\hline & Yes & 24 & 44 & 20 & 88 & \\
\hline \multirow[t]{2}{*}{ NFIncm } & No & 20 & 17 & 19 & 56 & $5.245^{*}$ \\
\hline & Yes & 63 & 65 & 69 & 197 & \\
\hline \multirow[t]{2}{*}{ Credit } & No Access & 79 & 78 & 69 & 226 & $30.322^{* * *}$ \\
\hline & Access & 0 & 24 & 3 & 27 & \\
\hline \multirow[t]{3}{*}{ District } & Amibara & 0 & 86 & 42 & 128 & $151.9^{* * *}$ \\
\hline & Awash Fentale & 54 & 0 & 30 & 84 & \\
\hline & Gewane & 25 & 16 & 0 & 41 & \\
\hline Continuous variables & Invasion level & $N$ & Mean & SD & & $F$ test \\
\hline \multirow[t]{3}{*}{ TLU } & Low & 79 & 14.48 & 8.80 & & $8.532^{* * *}$ \\
\hline & Medium & 102 & 21.28 & 21.32 & & \\
\hline & High & 72 & 11.90 & 11.41 & & \\
\hline \multirow[t]{3}{*}{ HHsize } & Low & 79 & 5.03 & 1.96 & & 1.717 \\
\hline & Medium & 102 & 5.31 & 1.71 & & \\
\hline & High & 72 & 5.64 & 2.48 & & \\
\hline \multirow[t]{3}{*}{ Age } & Low & 79 & 39.18 & 12.80 & & 0.973 \\
\hline & Medium & 102 & 41.79 & 11.95 & & \\
\hline & High & 72 & 40.86 & 13.14 & & \\
\hline \multirow[t]{3}{*}{ Edu } & Low & 79 & 1.63 & 1.57 & & 0.772 \\
\hline & Medium & 102 & 1.37 & 1.19 & & \\
\hline & High & 72 & 1.58 & 1.90 & & \\
\hline \multirow[t]{3}{*}{ Nrm_expert } & Low & 79 & 23.53 & 15.95 & & $4.646^{* *}$ \\
\hline & Medium & 102 & 20.84 & 14.39 & & \\
\hline & High & 72 & 28.18 & 17.02 & & \\
\hline \multirow[t]{3}{*}{ Dist_mkt } & Low & 79 & 33.96 & 14.91 & & $103.997^{* * *}$ \\
\hline & Medium & 102 & 11.27 & 8.39 & & \\
\hline & High & 72 & 15.40 & 8.53 & & \\
\hline \multirow[t]{3}{*}{ Dist_watrp } & Low & 79 & 0.36 & 0.62 & & $6.908^{* * *}$ \\
\hline & Medium & 102 & 2.02 & 4.34 & & \\
\hline & High & 72 & 2.93 & 6.23 & & \\
\hline \multirow[t]{3}{*}{ Dist_healt } & Low & 79 & 1.92 & 3.35 & & $7.055^{* * *}$ \\
\hline & Medium & 102 & 3.30 & 4.55 & & \\
\hline & High & 72 & 5.15 & 7.54 & & \\
\hline \multirow[t]{3}{*}{ Dist_school } & Low & 79 & 0.85 & 2.56 & & $5.741^{* * *}$ \\
\hline & Medium & 102 & 3.45 & 7.31 & & \\
\hline & High & 72 & 2.66 & 3.27 & & \\
\hline
\end{tabular}


Table 5 Estimated GPS: linear regression of Prosopis invasion level on covariates

\begin{tabular}{|c|c|c|c|}
\hline Variable & Coef. & Robust std. err. & Z \\
\hline$\overline{T L U}$ & 0.003 & 0.01 & 0.49 \\
\hline HHsize & 0.06 & 0.14 & 0.45 \\
\hline Sex & -0.23 & 0.06 & $-3.98^{* * *}$ \\
\hline Age & -0.11 & 0.06 & $-1.93^{*}$ \\
\hline Edu & -0.10 & 0.05 & $-1.81^{*}$ \\
\hline NFIncm & -0.01 & 0.05 & -0.26 \\
\hline Aid & -0.08 & 0.10 & -0.73 \\
\hline Credit & -0.24 & 0.10 & $-2.53^{* *}$ \\
\hline Participation & -0.11 & 0.05 & $-2.43^{* *}$ \\
\hline Nrm_expert & 0.00 & 0.00 & 0.78 \\
\hline Dist_mkt & 0.03 & 0.01 & $2.32^{* *}$ \\
\hline Dist_school & 0.02 & 0.01 & $2.87^{* * *}$ \\
\hline Dist_health & 0.02 & 0.01 & $2.64^{* * *}$ \\
\hline Dist_watrp & 0.02 & 0.03 & 0.72 \\
\hline HHExp & -0.00 & 0.00 & $-2.70^{* * *}$ \\
\hline HHExp square & 0.00 & 0.00 & $1.97^{* *}$ \\
\hline HHExp cube & -0.00 & 0.00 & -1.40 \\
\hline Age square & 0.00 & 0.00 & $2.06^{* *}$ \\
\hline Age cube & -0.00 & 0.00 & $-2.24^{* *}$ \\
\hline TLU square & -0.00 & 0.00 & -1.64 \\
\hline TLU cube & 0.00 & 0.00 & $2.09^{* *}$ \\
\hline HHsize square & -0.01 & 0.02 & -0.41 \\
\hline HHsize cube & 0.00 & 0.00 & 0.31 \\
\hline Edu square & 0.06 & 0.02 & $3.10^{* * *}$ \\
\hline Edu cube & -0.01 & 0.00 & $-3.42^{* * *}$ \\
\hline Dist_watrp square & -0.01 & 0.01 & -0.88 \\
\hline Dist_watrp cube & 0.00 & 0.00 & 0.55 \\
\hline Cons & 0.52 & 0.82 & 0.64 \\
\hline Adj R-squared & 0.0288 & & \\
\hline Number of obs & 253 & & \\
\hline
\end{tabular}

Source: own computation results based on survey data, 2016. ${ }^{* * *},{ }^{* *}$ and * means significant at the 1,5 and $10 \%$ probability levels, respectively

percentiles. Accordingly, covariate distribution was compared between three groups, i.e. group one (households with $\leq 26 \%$ invasion level), group two $(26 \%<$ household invasion level $\leq 41 \%$ invasion) and group three $(41 \%<$ household invasion level $\leq 100 \%$ invasion). Household observations in the first, second and third invasion groups were 84,77 and 92 , respectively.

The balance for each covariate was investigated by testing whether the mean in one of the three treatment groups was different from the mean of the other two treatment groups combined. This was done for each invasion group across the covariates. Reported on the left side of Table 6 are the standard two-sided $t$ tests for each covariate and each group. The results show imbalance of 10 (13) of $87 t$-statistics is greater than 1.96 (1.645) in absolute value. In general, when applying matching method for impact analysis, there is no standardized rule to determine how much imbalance is best. The proposed maximum differences for covariates range from 10 to 25\% (Austin 2009; Stuart et al. 2013). If this rule-of-thumb method is followed, the imbalance in the estimated GPS is tolerable since only $14.94 \%$ of the covariates were imbalance. Rather than stopping here and estimating DRF, the covariates were balanced by adjusting them on GPS. Test was also made for balancing property of the estimated GPS.

It is implemented by checking for weak unconfoundedness assumption. It was done through further dividing the evaluated GPS of each of the three groups into five blocks (defined by quintiles of the GPS). The GPS is evaluated at the mean of each group's invasion dose at a time. Households belonging to the first group and in block one are matched with households that are not members of the first group, i.e. who have a different level of invasion, but who have similar GPS evaluated at the mean invasion level of the first group lying in the first block as well. For every covariate, for instance, when group one was used as a treated group, comparisons were set between households in group 1 and block and those in groups 2 and 3 and block 1 to show differences in the two means and the total of five sets of mean differences. Five standard errors were obtained (one for each GPS interval). Combining the five differences in means and weighting that by the number of observations in each GPS block resulted in a mean difference of a covariate of group one (treatment group) and the rest of the two groups together (control group). After that, GPS-adjusted $t$-statistic was calculated and reported. The same procedure was repeated for another two times, alternately using group 2 and 3 as treated group. Summarized on the right hand-side of Table 6 are the $t$-statistics for all covariates. The distribution shows that most or a considerable number of households are on the common support.

The adjustment made for the GPS improved the balance of covariates (Table 6). After the adjustment, only three $t$-statistics were found to be larger than 1.96 (compared to 10 prior to adjustment) and four out of 87 were found to be larger than 1.645 (compared to 13 prior to adjustment). The adjustment improved covariates balance by $71.43 \%$. This implies that the invasion effect obtained by comparing a balanced pair is less likely to be biased (Hirano and Imbens 2004; Bia and Mattei 2007; Kluve et al. 2012; Guo and Fraser 2010; Liu and Florax 2014).

Finally, after the adjustment, the estimated GPS was evaluated at the representative point of each invasion interval. Table 7 summarizes the statistics of its distribution. The estimated overall GPS varies between 0.05 
Table 6 Balance of covariate accounting for the GPS: $t$-statistics for equality of means

\begin{tabular}{|c|c|c|c|c|c|c|}
\hline \multirow[t]{2}{*}{ Covariate } & \multicolumn{3}{|c|}{ Unadjusted } & \multicolumn{3}{|c|}{ GPS-adjusted } \\
\hline & {$[0.4,27]$} & {$[27,41]$} & {$[41,71]$} & {$[0.4,27]$} & {$[27,41]$} & {$[41,71]$} \\
\hline TLU & -2.08 & 1.03 & 1.31 & -2.35 & .81 & 1.04 \\
\hline HHsize & 0.05 & -0.45 & 0.41 & 0.61 & -0.38 & 0.33 \\
\hline Sex & -1.52 & 1.11 & -1.38 & -1.34 & 1.62 & -1.51 \\
\hline Age & 0.46 & -1.28 & 1.35 & 0.70 & -0.92 & 0.99 \\
\hline Edu & 1.05 & -0.61 & -0.53 & 1.33 & -0.93 & -0.22 \\
\hline Participation & -2.49 & 2.52 & 0.65 & -1.25 & 2.17 & 0.35 \\
\hline Nrm_expert & -1.06 & 1.29 & -0.33 & -1.00 & 1.57 & -0.09 \\
\hline Dist_mkt & -0.19 & 2.01 & -1.32 & 0.21 & 1.86 & -0.71 \\
\hline Dist_school & -2.44 & 0.62 & -1.18 & -1.54 & -0.14 & -1.38 \\
\hline Dist_health & -1.46 & 2.55 & -0.81 & -0.94 & 1.81 & -0.68 \\
\hline Dist_watrp & -1.74 & 0.53 & 1.11 & -0.58 & 0.02 & 0.23 \\
\hline NFIncm & 0.36 & -0.84 & 0.62 & 0.24 & -1.23 & 1.14 \\
\hline Aid & -0.73 & 1.61 & -0.78 & -0.64 & 1.29 & -1.13 \\
\hline Credit & -3.28 & 1.98 & -0.25 & -0.18 & 0.12 & -0.28 \\
\hline HHExp & -1.16 & 0.38 & 0.19 & -1.26 & 0.02 & 0.94 \\
\hline HHExp square & -0.18 & -0.19 & 0.34 & -0.36 & -0.61 & 1.02 \\
\hline HHExp cube & 0.33 & -0.57 & 0.36 & 0.25 & -0.95 & 0.91 \\
\hline Age square & 0.56 & -1.38 & 1.44 & 0.73 & -1.02 & 1.14 \\
\hline Age cube & 0.66 & -1.48 & 1.52 & 0.74 & -1.12 & 1.28 \\
\hline TLU square & -1.09 & 0.72 & 0.91 & -1.18 & 0.56 & 0.84 \\
\hline TLU cube & -0.63 & 0.54 & 0.61 & -0.65 & 0.46 & 0.59 \\
\hline HHsize square & 0.31 & -0.54 & 0.43 & 0.77 & -0.56 & 0.36 \\
\hline HHsize cube & 0.52 & -0.51 & 0.29 & 0.86 & -0.59 & 0.26 \\
\hline Edu square & 0.76 & -0.38 & -0.31 & 1.00 & -0.81 & 0.15 \\
\hline Edu cube & 0.65 & -0.53 & 0.04 & 0.84 & -0.94 & 0.45 \\
\hline Dist_mkt square & 0.28 & 2.13 & -1.69 & 0.75 & 2.00 & -0.16 \\
\hline Dist_mkt cube & 0.67 & 1.96 & -1.89 & 1.19 & 1.03 & -0.37 \\
\hline Dist_watrp square & -0.31 & 0.71 & -0.02 & -0.20 & 1.00 & 1.45 \\
\hline Dist_watrp cube & 0.17 & 0.54 & -0.33 & -0.15 & 1.14 & 1.17 \\
\hline
\end{tabular}

Source: own computation results based on survey data, 2016. Italicized numbers indicate significance at the $5 \%$ level

and 3.15 with a mean value of 2.31 . The three common support regions defined by each set of the GPS are shown (Table 8).

Consequently, the overall common support region would then lie between 0.51 and 3.15 by discarding nine

Table 7 Overall GPS and the GPS estimated at the mean of each treatment interval, Afar

\begin{tabular}{llllll}
\hline Variable & Observations & Mean & Std. dev. & Min & Max \\
\hline Overall GPS & 240 & 2.31 & 0.83 & 0.048 & 3.15 \\
Group 1 & 240 & 2.06 & 0.96 & 0.048 & 3.15 \\
Group 2 & 240 & 2.62 & 0.59 & 0.51 & 3.15 \\
Group 3 & 240 & 2.27 & 0.82 & 0.28 & 3.15 \\
\hline
\end{tabular}

Source: own computation results based on survey data, 2016 households from group 1, one household from group 2 and three households from group 3. Totally, 240 households were found to be in common support region for GPS estimation and for further analysis.

\section{Impact of Prosopis invasion on households per capita consumption expenditure: Dose-response function}

After confirming balancing property of the estimated GPS, Eq. (3) was used to estimate the conditional expectation of household per capita consumption expenditure as a function of two scalar variables (the invasion level and the GPS) and their interaction (Table 9). Note that the estimated coefficients do not have a causal interpretation. However, the results have two purposes in 
Table 8 Common support region

\begin{tabular}{|c|c|c|c|}
\hline $\begin{array}{l}\text { Treatment interval with } \\
\text { GPS estimate }\end{array}$ & Dosage group & Min. & Max. \\
\hline & & GPS1 & \\
\hline \multirow[t]{4}{*}{$\leq 0.26$} & Invasion $\leq 0.26$ & 0.0480443 & 3.153939 \\
\hline & Invasion > 0.26 & 0.0003194 & 3.153981 \\
\hline & $\begin{array}{l}\text { Common support } \\
\text { region }[0.0480443,3.1\end{array}$ & 3939] & \\
\hline & & GPS2 & \\
\hline \multirow[t]{4}{*}{0.26 to 0.41} & $\begin{array}{l}0.26<\text { invasion } \\
\leq 0.41\end{array}$ & 0.0800484 & 3.153943 \\
\hline & $\begin{array}{l}\text { Invasion } \leq 0.26 \text { and } \\
\text { invasion }>0.41\end{array}$ & 0.5073032 & 3.1538 \\
\hline & $\begin{array}{l}\text { Common support } \\
\text { region }[0.5073032,3.1\end{array}$ & 38] & \\
\hline & & GPS3 & \\
\hline \multirow[t]{3}{*}{$>0.41$} & Invasion > 0.41 & 0.0105841 & 3.153342 \\
\hline & Invasion $\leq 0.41$ & 0.2754641 & 3.153921 \\
\hline & \multicolumn{3}{|c|}{$\begin{array}{l}\text { Common support } \\
\text { region }[0.2754641,3.153342]\end{array}$} \\
\hline
\end{tabular}

Source: own computation results based on survey data, 2016

terms of showing ways of coming up with causal inference. These are generating average DRF and re-assessing whether the covariates introduce biases (Hirano and Imbens 2004; Liu and Florax 2014).

The final step of the GPS-based impact analysis was estimating the average DRF with causal inference. The average impact of Prosopis invasion on household per capita consumption expenditure at particular invasion intensity was estimated using Eq. (4). Following Hirano and Imbens (2004), the average potential outcome was estimated based on ten values of invasion level $0.1,0.2,0.3, \ldots, 1$. After this, the DRF at an invasion level $t$ was estimated as E[HHExp $(t)]$ and plotted. Then, the obtained average impact of invasion was plotted against the entire range of invasion distribution (Figure 3). The DRF was estimated within 95\% confidence band obtained using 1000 bootstrap $^{3}$ replications

Table 9 Estimated dose-response function for household per capita consumption expenditure

\begin{tabular}{llll}
\hline Consumption expenditure & Coef. & Std. err. & Z value \\
\hline Prosopis invasion & $12,232.97$ & 6059.19 & $2.02^{* *}$ \\
Prosopis invasion square & $-15,390.25$ & 8589.48 & $-1.79^{*}$ \\
GPS & -1287.42 & 1183.92 & -1.09 \\
GPS square & 419.99 & 257.11 & 1.63 \\
Invasion*GPS & -2082.39 & 1428.20 & -1.46 \\
Intercept & 3576.77 & 1502.97 & $2.38^{* * *}$ \\
Adj $R$-squared & 0.033 & & \\
Number of obs. & 240 & & \\
\hline
\end{tabular}

Source: own computation results based on survey data, 2016. ${ }^{* * *},{ }^{* *}$ and * means significant at the 1,5 and $10 \%$ probability levels, respectively (the same bootstrap was used for estimating GPS too). Figure 3 depicts the graphic representation of the average effect of treatment (dose-response) and its marginal effect (treatment effect) on households from the selected invasion intensity area. The marginal effect at an invasion level $t$ was estimated to be $E[H H E x p(t+0.1)]-E[\operatorname{HHExp}(t)]$. Figure 3 shows that there is no linear relationship between Prosopis invasion level and household per capita consumption expenditure. Three main segments are observed in the graph (see Figure 3). The graph suggests that initially, Prosopis invasion had positive net effect on household consumption expenditure and reached its optimum level at $22.23 \%$ invasion intensity.

After this optimum level, the graph starts decreasing showing the invasion's negative effect whose lowest point is at $39.74 \%$ invasion level. This indicates that the negative effect of Prosopis outweighs its benefit beyond 22.23\% invasion level and ultimately severs households' livelihood in the study area. This finding evidences in favour of the study's general hypothesis. That is, initially the benefits of Prosopis outweigh its costs and livelihood vulnerability up to a threshold point, but when the plant exceeds the expansion threshold, it is imperative to take appropriate economical measures to reverse the adverse ecological and socio-economic consequences (Shackleton et al. 2006).

After the dip point (at 39.74\%), the graph starts increasing and attains another maximum point at around $80 \%$ invasion level. However, this condition does not allow one to interpret the third segment of the graph as a causal relationship between invasion intensity and consumption expenditure. This is attributable to quite large confidence bands (Figure 3) emanated from small sample households in this segment. Even the maximum invasion cover attributed to the sample households was $71 \%$. Therefore, the result from GPS estimation indicates that the optimum average annual household per capita consumption expenditure is attained at around $22.23 \%$ invasion level and the corresponding optimum value is about 4,500 Ethiopian Birr (equal to USD 198). ${ }^{4}$ The concern here is where the optimum level of the Prosopis cover should be. Based on their lived experience, participants of the focus group discussion underlined that the invasive plant must be contained because not only it has adverse effect on their pasturelands, but also it may incapacitate the entire ecosystem of the pastoral livelihood. The main Prosopis dispersing agents in the area are wildlife and livestock. Thus, continuous monitoring and systematic controlling are required to contain the species to specific areas (Ilukor et al. 2016). This implies the need for establishing an appropriate institution that manages the invasion.

As can be seen on the right hand side of Figure 3, the magnitude of the dose effect varies based on Prosopis invasion intensity and non-linear. The non-linear relationship of invasion intensity and household consumption 

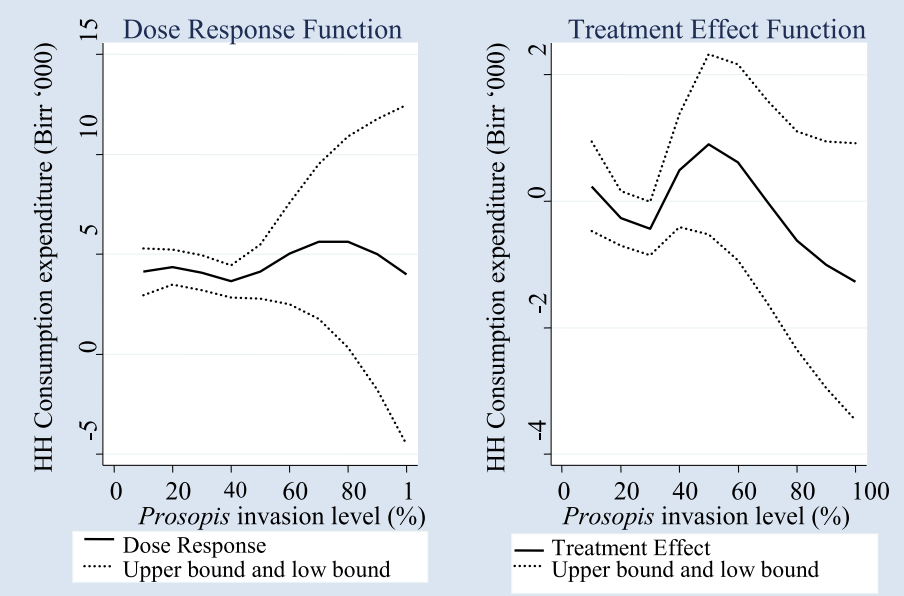

Figure 3 Estimated average dose-response function, estimated derivative, and 5\% confidence bands for household consumption expenditure (Quadratic). HH, household

expenditure was revealed in two ways. The first way is that a household from 20\% invasion level has almost similar outcome with a household from $60 \%$ invasion level. The second way is that the relationships are positive and negative for invasion level and invasion level squared (Table 9).

\section{Sensitivity analysis}

The main limitation in using the GPS method for impact analysis is the statistically non-testability of its key assumption, i.e. weak unconfoundedness. The plausible solution is to conduct different sensitivity checks for the main findings of the study (Kluve et al. 2012). On the basis of this recommendation, first, attempts were made to perform indirect checking through analyzing the relationship between treatment and other livelihood indicators which are supposed to be the determinants of the main outcome. The relationship between an invasion level and household consumption expenditure is the cumulative effects of the invasion level on different household livelihood indicators. Three livelihood indicators were used, and their average dose-responses were checked. They were per capita household income from livestock, per capita household income from charcoal and fuel wood sales and per capita household health expenditure. The presumption is that while Prosopis invasion decreases households' income from livestock (Wakie et al. 2016), it increases their income from charcoal and fuel wood sales (Haregeweyn et al. 2013). These two effects further affect household consumption in opposite directions. While the former has a negative effect, the later has a positive effect. Prosopis invasion also increases household health expenditure (Haregeweyn et al. 2013; Ayanu et al. 2015; Rogers et al. 2017) which in turn decreases household consumption expenditure.
The shape of the estimated DRF graph for annual household health expenditure is initially flat. This strongly suggests that low Prosopis invasion level has no significant effect on household health expenditure up to about $23 \%$ dose (Figure 4). However, the graph shows that after this optimum invasion intensity, household health spending increases with increase in the intensity of invasion. The marginal effect function shown on the right hand side of Figure 4 also reveals the same.

Figure 5 shows a convex decreasing response of household income from livestock to Prosopis invasion intensity (Figure 5). The figure indicates that within a reasonable band width, DRF declines. The worst effect of Prosopis invasion on household income from livestock is seen at $46 \%$ invasion cover. After this cover level, pastoralist households may be compelled to leave the area permanently. The figure, in addition, appears to suggest that income from livestock increases after this optimum level. There is a caveat, however, to the interpretation of this condition. After $46 \%$ invasion intensity, one cannot with certainty take the effect since the large confidence bands resulting from the small number of observations make it difficult to accurately estimate the effect. The marginal effects of additional invasion increase with increase in the level of invasion cover.

Figure 6 reveals that household income from charcoal and fuel wood sales increases with increase in the level of Prosopis invasion cover. All of the three livelihood indicators have relationships with Prosopis invasion, thus confirming the study's priori expectations. The results strengthen the study's finding on non-linear effects of Prosopis invasion cover on households' consumption expenditure. The optimum level of invasion is about $22.23 \%$ Prosopis cover of the total area. 

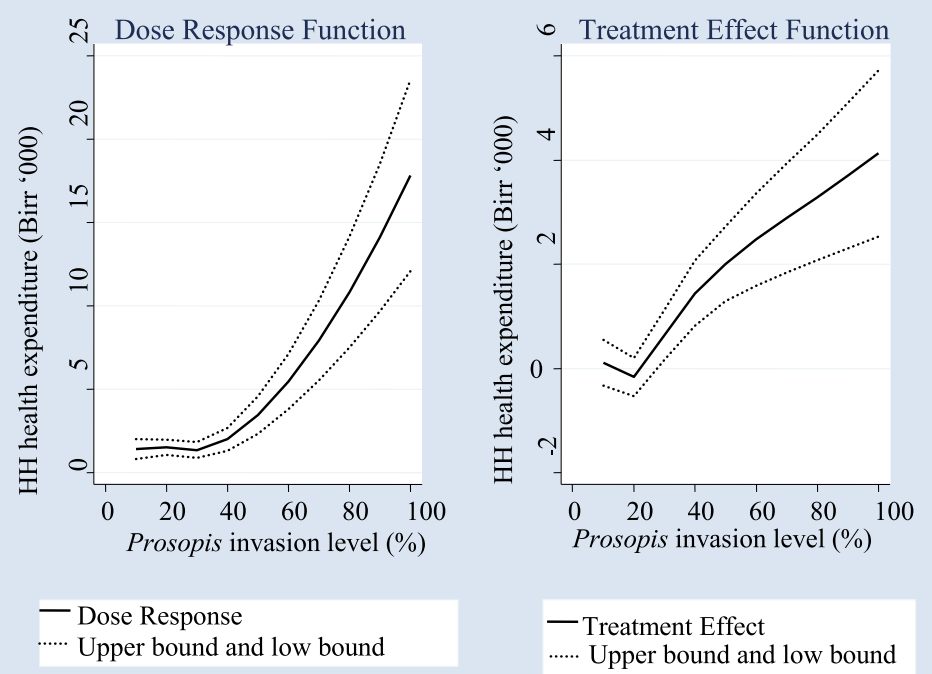

Figure 4 Estimated dose-response function, estimated derivative, and 5\% confidence bands for household health expenditure. HH, household

The second way of checking the main result of the study was by relaxing the estimation model specification. Parallel to the study's main specification, which is quadratic function, cubic specification was used to make DRF estimation (Figure 7). The figure summarizes results for the DRF for cubic polynomial model specification. Except for some details, the optimum invasion level is at about $21.52 \%$. The shape of the graph is quite similar with the result from the main model specification used in the study. One can say that in such a non-experimental impact analysis, the two optimum invasion levels are not critically different. Thus, results from both specifications indicate that Prosopis invasion has non-linear effects on annual household consumption expenditure of pastoralist and agro-pastoralist households in the study area. The optimum invasion cover after which the costs of invasion outweigh its benefits is about $22.23 \%$.

The crucial finding of the study is that Prosopis invasion has non-linear effects on household per capita consumption expenditure and the optimum invasion cover is at $22.23 \%$ which is robust.

\section{The implications of the findings for managing invasion of Prosopis}

The study revealed that Prosopis invasion cover has a non-linear causal relationship with household per capita

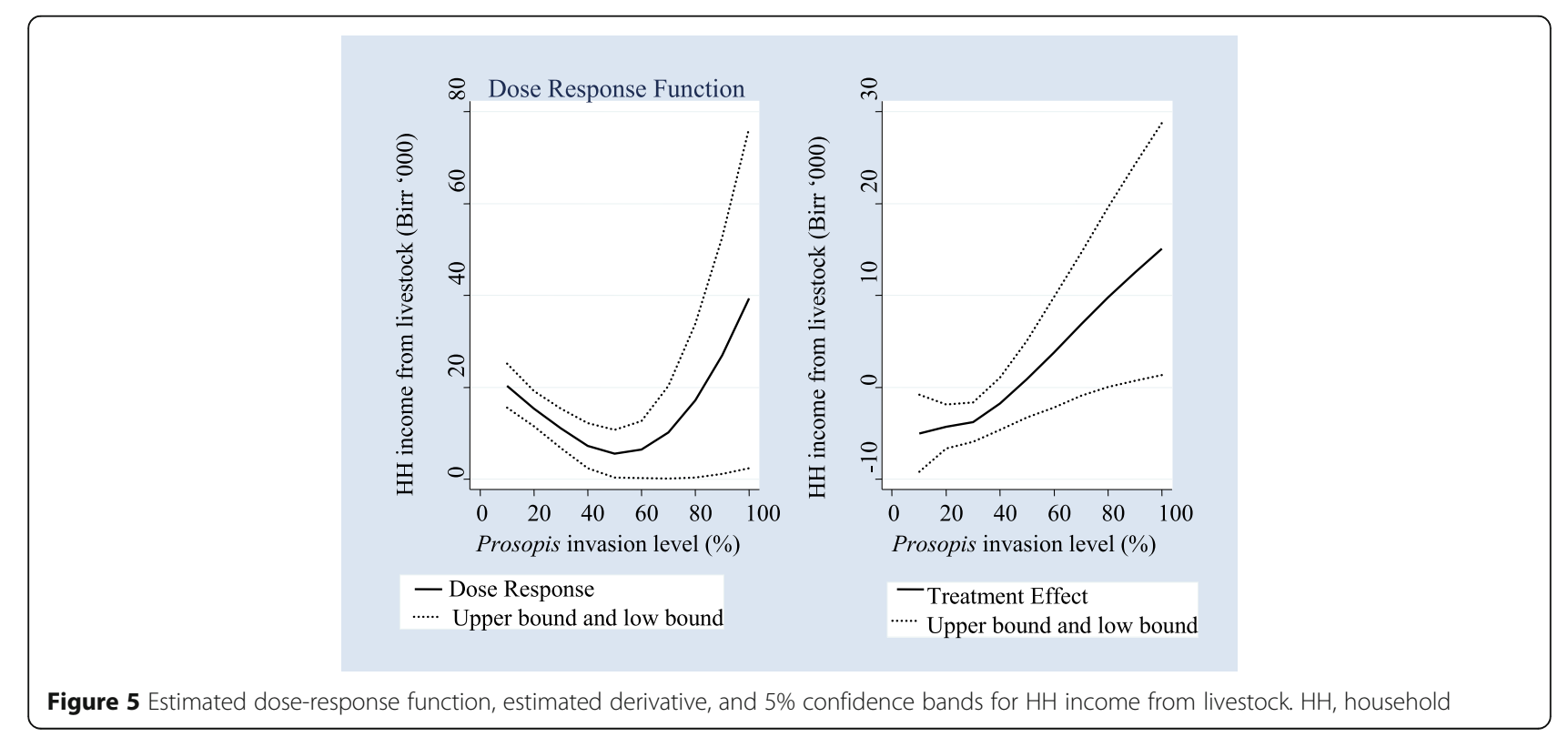



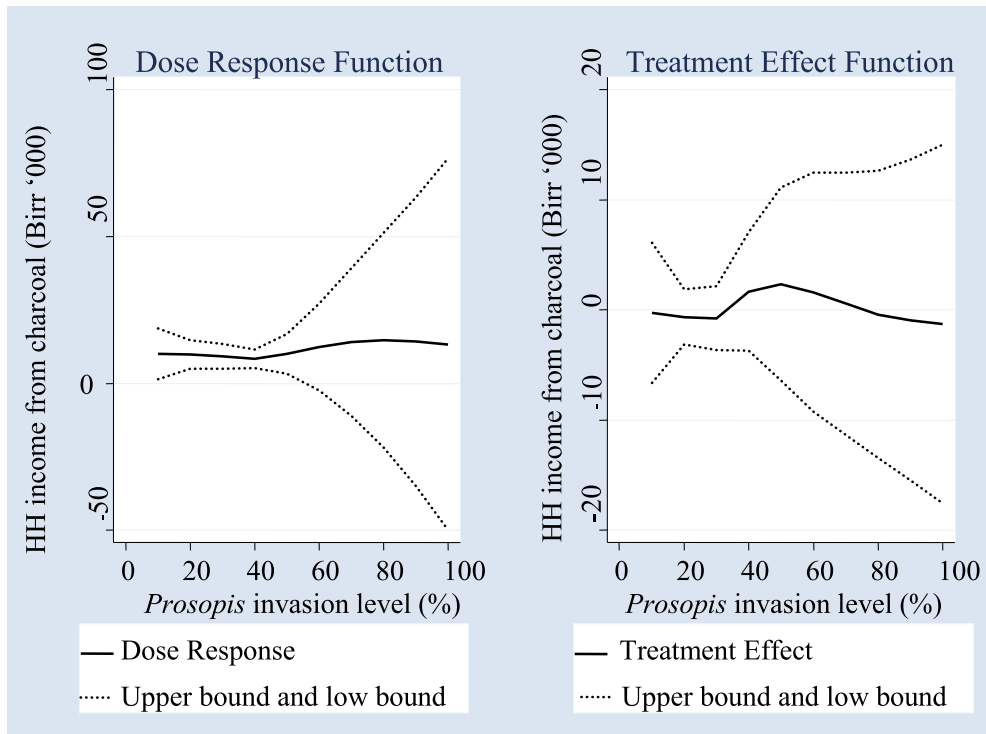

Figure 6 Estimated dose-response function, estimated derivative, and 5\% confidence bands for household income from charcoal and fuel wood sales. $\mathrm{HH}$, household

consumption expenditure. At a low level of invasion, Prosopis has a positive effect on rural household consumption expenditure. This relationship changes its sign after $22.23 \%$ invasion cover of the species. This main finding supports the previous findings that Prosopis has both positive and negative effects on the livelihood of households living in Prosopis-infested areas. In the same way as other invasive alien trees (van Wilgen and Richardson 2014) with both benefits and adverse effects, Prosopis invasion in the Afar Region may create dilemmas that affect decisions over how it should be managed.
The findings of this study disfavour a total eradication of the plant given the obvious socio-economic benefits and ecological benefits the plant provides at its low level density (e.g. Maundu et al. 2009; Haji and Mohammed 2013; Zeray et al. 2017). Eradication becomes a plausible option solely when the plant population is localized and when the size of the coverage is relatively small (van Wilgen and Richardson 2014; Ilukor et al. 2016). In a context where the invasive species has dominantly established itself and directly or indirectly become the base for the local communities' subsistence and income generation, empirically

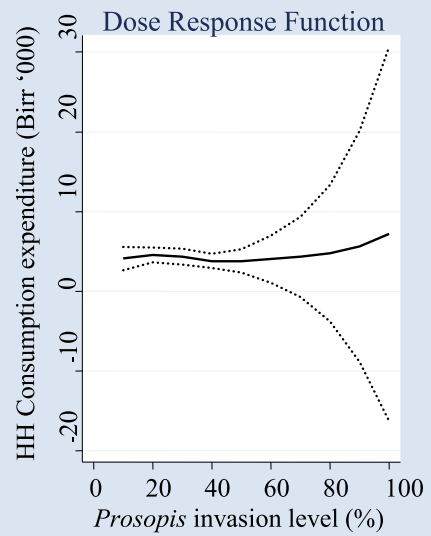

- Dose Response ...... Upper bound and low bound

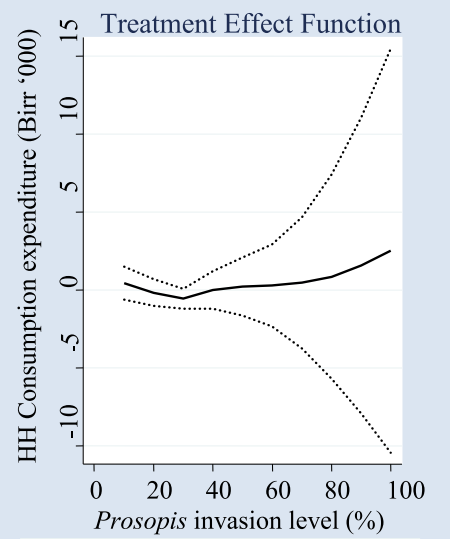

- Treatment Effect

…... Upper bound and low bound

Figure 7 Estimated dose-response function, estimated derivative, and 5\% confidence bands for household consumption expenditure (Cubic). $\mathrm{HH}$, household 
grounded, properly planned and integrated actions should be taken towards containing the invasion to an ecologically and economically optimum threshold level. This is a management practice that van Wilgen and Richardson (2014) refer to as holistic and collaborative management approach. On their part, Mosweu et al. (2013) see practices that promote multi-stakeholder participatory approaches as aspects of an integrated environmental management paradigm that enhance management success. In a situation where the structure and functions of an ecosystem have changed, the appropriate measures to be taken are controlling further invasion and recovering the affected areas (Gordon 1998). If properly planned and implemented, these and other participative, integrated and adaptive management practices and processes may help confront the complex problems and uncertainties associated with invasion (Shackelford et al. 2013; Ilukor et al. 2016). For instance, preventing further expansion, confining the spread of the species to bare lands where other plant species are rarely adaptive, clearing them from productive lands and using productive lands permanently are some of the strategies through which the destructive effects of the species can be effectively minimized (Shackleton et al. 2016).

Previous studies have also stressed that systematic and adaptive ways of controlling the expansion of the plant are sound solutions as a complete eradication is not only difficult but also socio-environmentally speaking untenable (e.g. Seid 2012; Haregeweyn et al. 2013; Ayanu et al. 2015; Ilukor et al. 2016; Wakie et al. 2016). There are obvious economic conflicts over eradication as a management option (Seid 2012). The role of the plant in the dryland economy is unquestionable. In the context of the study area, households that generate their income mainly through producing and selling charcoal are against eradication (Haregeweyn et al. 2013; Ilukor et al. 2016). In addition, eradication is extremely labour intensive and expensive (Ayanu et al. 2015). Eradication is not a sound option from the ecological point of view as well since the plant plays greater role in reducing wind erosion and microclimate regulation (Haregeweyn et al. 2013). Further, the fact that the seeds of Prosopis species remain in the soil bank and their capability to germinate after passing through the digestive systems of animals are among the biological characteristics that foster the invasion of the species and make its complete eradication literally impractical (Berhanu and Tesfaye 2006).

In a nutshell, social and institutional contexts of pastoralists should be considered in designing and implementing any management strategy (Rogers et al. 2017). Supporting this argument, for instance, though the government and NGOs tried to manage Prosopis invasion through utilization by charcoal production (EARO and HADRA 2005), this management was not successful so that Ethiopian government banned charcoal production in Afar Region (Wakie et al. 2016). One reason could be the culture of pastoralist communities, i.e. pastoralists have no experience and knowledge on charcoal production and only few Afar people benefited from charcoal production (Datona 2014; Ilukor et al. 2016). In addition, beyond livelihoods and environmental costs, charcoal production exacerbated intra and inter-tribe conflicts in Afar (Rogers et al. 2017). Haregeweyn et al. (2013) pinpointed that the introduction of charcoal making as a means of controlling Prosopis is quickly robbing the remaining forest cover by non-Afar highlanders. By the name of Prosopis management through utilization, non-Afar charcoal makers deforested native trees. This might have emanated from government policy direction which generally marginalizes pastoralism as a base of livelihoods and pastoralists' culture but presses on forced sedentralization. In pastoralist areas of Afar, land appropriation is common for large-scale private and government commercial farm investments (Jacoby et al. 2002) so that customary land management is weakened. Therefore, land security through the land tenure system seems to have noticeable implications for Prosopis effects and its management (Hundie and Padmanabhan 2008; Ilukor et al. 2016). Institutional arrangements connected to land security, therefore, seem to be a gray area of consideration to incentivize and motivate local communities (Tilahun et al. 2017) in Prosopis management in Afar Region.

\section{Conclusions}

This study attempted to estimate the average causal impact of Prosopis invasion cover on per capita consumption expenditure of pastoralist and agro-pastoralist households in Afar Region. Dose-response function was estimated based on the generalized propensity score under a weak unconfoundedness assumption. In this study, conditional on sample households' covariates, Prosopis invasion intensities are independent of household per capita consumption expenditure. In order to increase the credibility, the assumption set for identification, and check the robustness of the model used in the study, relevant covariates were included and different sensitivity analyses were performed.

The results show the existence of heterogeneous effects along different Prosopis invasion doses or levels. Three general effects were uncovered between Prosopis invasion intensity and household per capita consumption expenditure. Initially, household consumption expenditure increases with invasion intensity and exceeds the threshold level after which the relationship starts to inverse. The optimum invasion level is at $22.23 \%$, and the corresponding annual household per capita consumption expenditure is about 4,500 Ethiopian Birr (equal to USD 198). This was revealed by considering the continuous nature of Prosopis 
invasion level among households within 100-m radius of their permanent homestead. The findings suggest that containing Prosopis invasion to less density (less than $22.23 \%$ of an area) may benefit the livelihoods of the region. The implication is that management strategies should take into account the invasion levels of each locality and the current socio-economic as well as ecological benefits of the plant, prior to instead of considering its complete removal as the only vital solution. Eradication ultimately becomes an effective action if it cannot give assurance on the potential of the species to re-introduce itself.

\section{Endnotes}

${ }^{1}$ Our Skewness and Kurtosis values are not significantly different from 0 and 3 respectively.

${ }^{2}$ To estimate standard errors of DRF.

${ }^{3}$ Note that only households ( 240 households) in common support region were included in GPS and DRF estimations.

${ }^{4}$ Birr refers to Ethiopian local currency.

\section{Additional file}

Additional file 1: Estimated GPS and test disturbances' distributions. (DOCX $66 \mathrm{~kb}$ )

\section{Abbreviations}

CSA: Central Statistical Agency of Ethiopia; DRF: Dose-response function; GPS: Generalized propensity score; IAS: Invasive alien species; TLU: Tropical livestock unit

\section{Acknowledgements}

The College of Agriculture and Environmental Sciences, Haramaya University, has facilitated the whole research process. The authors are also grateful to rural development experts in Gabi Rasu Zone of Afar Region of Ethiopia for their cooperation during the survey.

\section{Funding}

This work was financially supported by the Woody Weeds project which was funded by the Swiss National Science Foundation and the Swiss Agency for Development and Cooperation under the Research for Development (r4d) programme.

\section{Availability of data and materials}

Upon request, data in Excel format can be supplied by the corresponding author.

\section{Authors' contributions}

All authors actively participated in data tool design, data analysis and writeup of this manuscript. Therefore, we confirm that the manuscript has been read and approved by all the authors.

\section{Competing interests}

The authors declare that they have no competing interests.

\section{Publisher's Note}

Springer Nature remains neutral with regard to jurisdictional claims in published maps and institutional affiliations.

\section{Author details}

'School of Agricultural Economics and Agribusiness, Haramaya University, P.O. Box 50, Dire Dawa, Ethiopia. ${ }^{2}$ Water and Land Resource Centre, Addis
Ababa University, Ethiopia, P.O. Box 3880, Addis Ababa, Ethiopia. ${ }^{3}$ CABI Switzerland, Rue des Grillons 1, 2800 Delémont, Switzerland.

Received: 16 January 2018 Accepted: 2 May 2018

Published online: 26 September 2018

\section{References}

Admasu, D., 2008. Invasive plants and food security: The case of Prosopis juliflora in the Afar region of Ethiopia, 1-13. FARM-Africa, IUCN, Ethiopia.

Austin, P. 2009. Balance diagnostics for comparing the distribution of baseline covariates between treatment groups in propensity-score matched samples. Statistics in Medicine 28: 3083-3107.

Ayanu, Y., A. Jentsch, D. Müller-Mahn, S. Rettberg, C. Romankiewicz, and T. Koellner. 2015. Ecosystem engineer unleashed: Prosopis juliflora threatening ecosystem services? Regional Environmental Change 15 (1): 155-167.

Baulch, B., and J. Hoddinott. 2000. Economic mobility and poverty dynamics in developing countries. The Journal of Development Studies 36 (6): 1-24.

Berhanu, A., and G. Tesfaye. 2006. The Prosopis dilemma, impacts on dryland biodiversity and some controlling methods. Journal of the Drylands 1 (2): 158-164.

Bia, M., and A. Mattei. 2007. Application of the generalized propensity score. Evaluation of public contributions to Piedmont enterprises, POLIS working paper, 80.

Brookhart, M. S. Schneeweiss, K. Rothman, R. Glynn, J. Avorn, and T. Stürmer. 2006. Variable selection for propensity score models. American Journal of Epidemiology 163 (12): 1149-1156.

CSA (Central Statistical Agency of Ethiopia). 2008. Summary and statistical report of the 2007. Population and housing census. Central Statistical Agency of Ethiopia, Addis Ababa, Ethiopia.

CSA (Central Statistical Agency of Ethiopia). 2015. Statistical abstract 2015. Central Statistical Agency of Ethiopia, Addis Ababa, Ethiopia.

Datona, M., 2014. 15. Socio-economic impacts of Prosopis juliflora-related charcoal trade in Gewane Woreda, Afar Region. Managing Prosopis Juliflora for better (agro-) pastoral Livelihoods in the Horn of Africa, pp.129.

EARO, and HADRA. 2005. Controlling the spread of Prosopis in Ethiopia by its utilisation. Addis Ababa: Agricultural Research Organization (EARO) and Henry Doubleday Research Association (HADRA).

Ellis, F. 1993. Peasant economics: Farm household and agrarian development. 2nd ed. Cambridge: Cambridge University Press.

Fraser, M.W., S. Guo, A.R. Ellis, A.M. Thompson, T.L. Wike, and J. Li. 2011. Outcome studies of social, behavioral, and educational interventions: Emerging issues and challenges. Research on Social Work Practice 21 (6): 619-635.

Garrido, M.M., A.S. Kelley, J. Paris, K. Roza, D.E. Meier, R.S. Morrison, and M.D. Aldridge. 2014. Methods for constructing and assessing propensity scores. Health Services Research 49 (5): 1701-1720.

Gertler, J., S. Martinez, P. Premand, B. Rawlings, and J. Vermeersch. 2011. Impact evaluation in practice. Washington DC: The International Bank for Reconstruction and Development / The World Bank.

Gordon, D.R. 1998. Effects of invasive, non-indigenous plant species on ecosystem processes: Lessons from Florida. Ecological Applications 8 (4): 975-989.

Guardabascio, B. and M. Ventura. 2013. Estimating the dose-response function through the GLM approach. http://mpra.ub.uni-muenchen.de/45013/. Accessed 15 June 2017

Guo, S., and M.W. Fraser. 2010. Propensity score analysis: Statistical methods and analysis. 2nd ed. London: SAGE publications, Inc..

Haji, J., and A. Mohammed. 2013. Economic impact of Prosopis juliflora on agropastoral households of Dire Dawa Administration, Ethiopia. African Journal of Agricultural Research 8 (9): 768-779.

Haregeweyn, N. A. Tsunekawa, M. Tsubo, D. Meshesha, and A. Melkie. 2013. Analysis of the invasion rate, impacts and control measures of Prosopis juliflora: A case study of Amibara District, Eastern Ethiopia. Environmental Monitoring and Assessment 185 (9): 7527-7542.

Hirano, K., and G.W. Imbens. 2004. The propensity score with continuous treatments. Applied Bayesian modeling and causal inference from incompletedata perspectives 226164: 73-84

Ho, D., K. Imai, G. King, and E. Stuart. 2007. Matching as nonparametric preprocessing for reducing model dependence in parametric causal inference. Political Analysis 15: 199-236.

Hundie, B. and Padmanabhan, M., 2008. The transformation of the commons: Coercive and non-coercive ways. Collective and Property Rights for Poverty Reduction: Lessons from a Global Research Project, IFPRI, Washington DC. 
Ilukor, J., S. Rettberg, A. Treydte, and R. Birner. 2016. To eradicate or not to eradicate? Recommendations on Prosopis management in Afar, Ethiopia, from an interdisciplinary perspective. Pastoralism 6 (1): 14.

Inkermann, H., 2014. Gender aspects of Prosopis spread in Baadu area, Afar Regional State, Ethiopia-perceptions, impacts and coping strategies. Proceedings of the Regional Conference May 1-May 2, 2014, Addis Ababa, Ethiopia.

Jacoby, G., G. Li, and D. Rozelle. 2002. Hazards of expropriation: Tenure insecurity and investment in rural China. American Economic Review 92 (5): 1420-1447.

Jahnke, H.E., and H.E. Jahnke. 1982. Livestock production systems and livestock development in tropical Africa. Vol. 35. Kiel: Kieler Wissenschaftsverlag Vauk.

Kassie, M., M. Jaleta, and A. Mattei. 2014. Evaluating the impact of improved maize varieties on food security in rural Tanzania: Evidence from a continuous treatment approach. Food Security 6 (2): 217-230.

Khandker, R., B. Koolwal, and A. Samad. 2010. Handbook on impact evaluation: Quantitative methods and practices. Washington DC: The World Bank.

Kluve, J., H. Schneider, A. Uhlendorff, and Z. Zhao. 2012. Evaluating continuous training programmes by using the generalized propensity score. Journal of the Royal Statistical Society: Series A (Statistics in Society) 175 (2): 587-617

Li, J., and M.W. Fraser. 2015. Evaluating dosage effects in a social-emotional skills training program for children: An application of generalized propensity scores. Journal of Social Service Research 41 (3): 345-364.

Liu, J., and R. Florax. 2014. The effectiveness of international aid: A generalized propensity score analysis. In 2014 Annual Meeting, July 27-29, 2014, Minneapolis, Minnesota, USA (no. 169804). USA: Agricultural and Applied Economics Association.

MA (Millennium Ecosystem Assessment). 2005. Ecosystems and human well-being: Synthesis. Washington DC: Island Press.

Matuschke, I., and M. Qaim. 2008. Seed market privatisation and farmers' access to crop technologies: The case of hybrid pearl millet adoption in India. Journal of Agricultural Economics 59 (3): 498-515.

Maundu, P., S. Kibet, Y. Morimoto, M. Imbumi, and R. Adeka. 2009. Impact of Prosopis on Kenya's semi-arid and arid ecosystems and local livelihoods. Biodiversity 10 (2-3): 33-50

McCulloch, N. and Baulch, B., 1999. Distinguishing the chronically from the transitorily poor: Evidence from Pakistan.

Mehari, Z.H. 2015. The invasion of Prosopis juliflora and Afar pastoral livelihoods in the Middle Awash area of Ethiopia. Ecological Processes 4 (1): 13.

Mosweu, S., C. Munyati, T. Kabanda, M. Setshogo, and M. Muzila. 2013. Prosopis L. invasion in the south-western region of Botswana: The perceptions of rural communities and management options. Natural Resources 4: 496-505.

Müller-Mahn, D., S. Rettberg, and G. Getachew. 2010. Pathways and dead ends of pastoral development among the Afar and Karrayu in Ethiopia. The European Journal of Development Research 22 (5): 660-677.

Mwangi, E., and B. Swallow. 2008. Prosopis invasion and rural livelihoods in the Lake Baringo area of Kenya. Conservation and Society 6 (2): 130.

Myers, J., J. Rassen, J. Gagne, K. Huybrechts, S. Schneeweiss, K. Rothman, M. Joffe, and R. Glynn. 2011. Effects of adjusting for instrumental variables on bias and precision of effect estimates. American Journal of Epidemiology 174 (11): 1213-1222.

Patorno, E., Grotta, A., Bellocco, R. and Schneeweiss, S., 2013. Propensity score methodology for confounding control in health care utilization databases. Epidemiology, Biostatistics and Public Health, 10(3), e8940-1- e8940-16.

Pejchar, L., and H.A. Mooney. 2009. Invasive species, ecosystem services and human well-being. Trends in Ecology \& Evolution 24 (9): 497-504.

Pimentel, D., S. McNair, J. Janecka, J. Wightman, C. Simmonds, C. O'connell, E. Wong, L. Russel, J. Zern, T. Aquino, and T. Tsomondo. 2001. Economic and environmental threats of alien plant, animal, and microbe invasions. Agriculture, Ecosystems \& Environment 84 (1): 1-20.

Rogers, P., F. Nunan, and A.A. Fentie. 2017. Reimagining invasions: The social and cultural impacts of Prosopis on pastoralists in southern Afar, Ethiopia. Pastoralism 7 (1): 22

Rosenbaum, P.R., and D.B. Rubin. 1983. The central role of the propensity score in observational studies for causal effects. Biometrika 70 (1): 41-55.

Rubin, D. 1997. Estimating causal effects from large data sets using propensity scores. Annals of Internal Medicine 127 (8): 757-763.

Seeger, J., T. Kurth, and A. Walker. 2007. Use of propensity score technique to account for exposure-related covariates: An example and lesson. Medical Care 45 (10): S143-S148

Seid, M.J. 2012. Household perception about Prosopis juliflora and its effect on pastoral livelihood diversification strategy: The case of Gewane district in Afar regional state, Ethiopia. IJASR 2 (3): 21-51.
Sertse, D., \& N. M. Pasiecznik. 2005. Controlling the spread of Prosopis in Ethiopia by its utilisation. Publication., from Henry Doubleday Research Association (HDRA), Coventry, UK

Shackelford, N., R.J. Hobbs, N.E. Heller, L.M. Hallett, and T.R. Seastedt. 2013. Finding a middle-ground: The native/non-native debate. Biological Conservation 158: 55-62.

Shackleton, M., D. McGarrt, J. Gambiza, E. Shackleton, and C. Fabricius. 2006. Assessing the effect of invasive alien species on rural livelihoods: Case examples and a frame work from South Africa. Human Ecology 35: 113-127.

Shackleton, R., D. Le Maitre, B. van Wilgen, and D. Richardson. 2016. Identifying barriers to effective management of widespread invasive alien trees: Prosopis species (mesquite) in South Africa as a case study. Global Environmental Change 38: 183-194.

Silva, A.M., A.R. Silva, A.M. Pinheiro, S.R. Freitas, V.D. Silva, C.S. Souza, and J.B. Hughes. 2007. Alkaloids from Prosopis juliflora leaves induce glial activation, cytotoxicity and stimulate NO production. Toxicon 49: 601-614. https://doi. org/10.1016/j.toxicon.2006.07.037.

Simberloff, D., J.L. Martin, P. Genovesi, V. Maris, D.A. Wardle, J. Aronson, F. Courchamp, B. Galil, E. García-Berthou, M. Pascal, and P. Pyšek. 2013. Impacts of biological invasions: What's what and the way forward. Trends in Ecology \& Evolution 28 (1): 58-66.

Stuart, E., B. Lee, and F. Leacy. 2013. Prognostic score-based balance measures can be a useful diagnostic for propensity scores in comparative effectiveness research. Journal of Clinical Epidemiology 66: S84-S90.

Tilahun, M., R. Birner, and J. Ilukor. 2017. Household-level preferences for mitigation of Prosopis juliflora invasion in the Afar region of Ethiopia: A contingent valuation. Journal of Environmental Planning and Management 60 (2): 282-308

van Wilgen, B., and D. Richardson. 2014. Challenges and trade-offs in the management of invasive alien trees. Biological Invasions 16 (3): 721-734.

van Wilgen, B.W., D.M. Richardson, D.C. Le Maitre, C. Marais, and D. Magadlela. 2001. The economic consequences of alien plant invasions: Examples of impacts and approaches to sustainable management in South Africa. Environment, Development and Sustainability 3 (2): 145-168.

Wakie, T., M. Laituri, and H. Evangelista. 2016. Assessing the distribution and impacts of Prosopis julifora through participatory approaches. Applied Geography 66: 132-143.

Wardle, D.A., R.D. Bardgett, R.M. Callaway, and W.H. Van der Putten. 2011. Terrestrial ecosystem responses to species gains and losses. Science 332 (6035): 1273-1277.

Wise, R.M., B.W. Van Wilgen, and D.C. Le Maitre. 2012. Costs, benefits and management options for an invasive alien tree species: The case of mesquite in the Northern Cape, South Africa. Journal of Arid Environments 84: 80-90.

Zeray, N., B. Legesse, J. Mohamed, and M. Aredo. 2017. Impacts of Prosopis invasion on livelihoods of pastoral and agro-pastoral households of Dire Dawa Administration, Ethiopia. Pastoralism 7 (1): 7

Zhai, F., C.C. Raver, S.M. Jones, C.P. Li-Grining, E. Pressler, and Q. Gao. 2010. Dosage effects on school readiness: Evidence from a randomized classroombased intervention. Social Service Review 84 (4): 615-655.

\section{Submit your manuscript to a SpringerOpen ${ }^{\odot}$ journal and benefit from:}

- Convenient online submission

- Rigorous peer review

- Open access: articles freely available online

High visibility within the field

Retaining the copyright to your article

Submit your next manuscript at $\boldsymbol{\nabla}$ springeropen.com 